\title{
Temporal experience in mania
}

\author{
Marcin Moskalewicz ${ }^{1,2,3}$ (D) $\cdot$ Michael A. Schwartz ${ }^{4}$
}

Published online: 8 March 2018

(C) The Author(s) 2018. This article is an open access publication

\begin{abstract}
The paper examines both the phenomenology of the manic self as well as critical aspects of manic neurobiology, focusing, with respect to both domains, on manic temporality. We argue that the distortions of lived time in mania exceed mere acceleration and are fundamental for manic affectivity. Mania involves radical acceleration and radical asynchronicity, which result in an instantaneous existence. People with mania rebel against the facticity of reality and suffer from an existential leap towards the future, in which the self abandons normal temporal boundaries. Excerpts from the interviews with persons with mania who experienced psychosis illustrate this phenomenon. Commenting upon disrupted circadian rhythms in mania and the role of lithium in its treatment the paper posits manic temporality as the link through which manic phenomenology and manic neurobiology intertwine.
\end{abstract}

Keywords Time perception - Lived time - Acceleration · Timelessness · Eternity · Psychosis $\cdot$ Lithium $\cdot$ Biological clock $\cdot$ Circadian rhythms

\section{Introduction}

Disturbances of temporality in mania, readily apparent in the disorder, are nonetheless under-emphasized in present-day accounts. They are not included among the criteria for a manic episode in DSM-IV, DSM-5, ICD-10 or the Beta Version of ICD-11. Only the frequency and length of manic episodes that situates them in clock time is diagnostically relevant. Lived temporal experience is disregarded. Nevertheless, the aberrant experience

Marcin Moskalewicz

moskalewicz@gmail.com

1 Department of Social Sciences, Poznan University of Medical Sciences, Poznań, Poland

2 The Oxford Research Centre in the Humanities (TORCH), University of Oxford, Oxford, UK

3 Res Publica Foundation, Warsaw, Poland

4 Department of Psychiatry and Department of Humanities in Medicine, Texas A\&M Health Science Center, Round Rock, TX, USA 
of time is central to the disorder. As Eugène Minkowski already noticed, mania is a "manifestation of a mental subduction in time" (Minkowski 1970: 296). Our intention in this paper is to examine both the phenomenology of mania as well as critical aspects of manic neurobiology, focusing, with respect to both domains, on manic temporality. Manic temporality, we will come to see, is a link, if not the link, through which manic phenomenology and manic neurobiology intertwine. Clarifying the details of such intertwining can cast a clear light upon essential features of the manic self. Major implications for the treatment of mania ensue - both pharmacologically with substances such as lithium, and non-pharmacologically with the aid of zeitgebers.

\section{Manic acceleration}

Common sense thinking associates mania with an accelerated tempo, and rightly so. Studies of time perception have found that, as far as short durations (at the seconds range) are concerned, manic persons tend to underestimate clock time in time production tasks, and overestimate in temporal durations tasks (Tysk 1984; Tysk 1985). These findings indicate that the persons' subjective feeling of the flow of time is faster than that of controls. According to the internal clock hypothesis, it means that their internal clock operates faster and, therefore, they have subjectively "more" time at their disposal. However, these findings are valid only in the seconds range, and not in the minutes and hours range, when a memory component partakes in the temporal judgment. With the change in focus from the perception to the duration of longer intervals, manic persons tend to experience longer durations as shorter durations (underestimating and not overestimating time) (Mezey and Knight 1965; Lehmann 1967). In other words, their time shrinks retrospectively. One hypothesis is that a positive emotional attitude characterizing a manic disturbance leads to an underestimation of longer duration (in the hours range) and to the experience of external time as passing more quickly (Mezey and Knight 1965). This hypothesis, however, assumes that affectivity is more fundamental than temporal experience, whereas phenomenology suggests that it is the other way around. There is experimental evidence that fast thinking itself leads not only to an increase in positive affect but also extends beyond mood towards feelings of power, creativity, and grandiosity (Pronin and Wegner 2006; Pronin et al. 2008). What is more, the variability of thoughts - which can be posited as analogical to the manic flight of ideas - adds to the effect. A study showed that thought sequences that vary widely rather than revolve around a single theme produce more positive affect independently of the thoughts content (Pronin and Jacobs 2008). In manic persons, an increased tempo of listened music does not increase the tension but leads to the experience of gaiety (Nielzén and Cesarec 1982). Such music appears as more attractive. Manic persons' favorite (median) tempo of music is as fast as $152 \mathrm{~mm}$, and accordingly, they might find the standard tempo of human speech boring (Stein 1977; Stein 1988).

Time perception studies, however, by definition, measure only the reflective experience of time and not any deeper (pre-reflective) sense of temporality. Also, cognitive underestimation and overestimation of time do not equal the sense of time flying or dragging. Moreover, it must be remembered that acceleration, as Thomas Fuchs has aptly explained, is not simply relative to the objectified or clock time. It has to do with a loss of simultaneity with both natural rhythms and social, intersubjective temporality (Fuchs 2013). There is a 
continuum ranging from the (normal) experience of being too early and the concomitant necessity of waiting, through boredom and impatience, towards agitation and mania. A spectrum of emotional states corresponds to the scale of asynchronicity, but feeling "faster" than the external world is by no means pathological by itself.

In the proportional model of the manic-depressive spectrum, we can discern its two dimensions. 1) The continuum of severity that ranges from the lack of symptoms, through temperament, affective personality, to non-psychotic and psychotic mood disorders. 2) The continuum of mood that ranges from depression to mania (Angst 2007). ${ }^{1}$ We can see the continuity of temporal disturbance in an analogical way along the scale of asynchronicity where extreme acceleration would occupy its end point. Further on in this paper, we focus on such an extreme ideal-typical case. Disregarding the cycling dimension of illness, that is the frequency and length of mood changes in objective time, we analyze lived time underlying manic affectivity in its most extreme phase.

\section{Phenomenology of the manic self: Minkowski and Binswanger}

Neither the quantitative perception of time nor the affective dimension of tempo brings us to the core of manic temporality. Grasping its essence necessities a more structurally oriented phenomenological analysis. Minkowski observed that patients with mania do not unfold in time. They suffer from a distortion of syntony, i.e. affective contact with the environment. Taking advantage of the Bergsonian concept of duration, Minkowski explicated syntony in terms of lived synchronism between personal and ambient becoming. Crucially, he noticed that manic temporality transcends mere acceleration. The activity of manic people is not just faster and more rapid (which could be an advantage in life), but it is degraded (Minkowski 1970: 294-296). In mania, acceleration reaches a point in which the temporal structure of experience collapses. Quantity becomes quality - time speeds up to an extent that the bond between its three dimensions breaks down. Minkowski also noted that, unlike people with schizophrenia, those in manic states remain in contact with reality, even if they are unable to penetrate it. However, the contact is superficial and temporarily shrinking - a mere play between the instants of time, and not a lived duration. In speech, manic persons prefer a grammatical form of the present, but their lived present has no frontiers of past and future. Their existence is instantaneous. A contemporary empirical study confirms such an increased present and decreased future focus of manic subjects (Gruber et al. 2012). Compared to controls, they are in effect "stuck" in the present emotional moment.

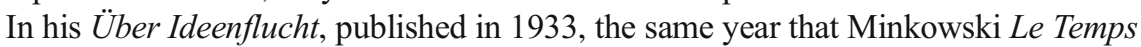
vécu appeared, Ludwig Binswanger provided a similar, though more elaborate argument. Unlike Minkowski, Binswanger followed Heidegger's, and not Bergson's, concepts. The book launched Binswanger's new approach - after a period of fascination by Husserl, he entered the Heideggerian phase of his work (Spiegelberg 1972). Binswanger's goal was to propose an existential anthropology of manic being-in-the-

\footnotetext{
${ }^{1}$ Beside type I bipolar disorder, less severe forms of the disorder exist, usually under the label of the continuous bipolar spectrum. There is continuity between common mood fluctuations and manic-depressive ones, analogical to that of hypertension. From the perspective of the bipolar spectrum, the key to illness lies not in its severity, but in cycling (Katzow et al. 2003).
} 
world, an anthropology (not ontology) presenting a particular mode of this being. It was a mode that was utterly different from the norm but not pathological per se. Before Binswanger, mainstream psychiatry, following eighteenth century psychological ideas dividing the mind into different, independent faculties - emotions, reason and will considered mania as a disorder of associations (Colillas 2016). By shifting attention to existence, Binswanger noticed that the flight of ideas, which is pathognomonic for mania, can be considered its symptom only in the context of the whole of the disordered way of being and its own world (Binswanger 1992).

Analyzing the meaning of utterances of his patients, Binswanger described the spatial structure of the disorder as eradication of distance. Mania involves shrinking of lived space. Analogically, lived time shortens to the extent of becoming punctual. The temporal structure of the disorder (underpinning its characteristic manifestation in the form of the flight of ideas) is discontinuous. A manic person lives in an inauthentic and merely "momentary" present, which - as Minkowski also argued - is not a true present. Manic "festive" joy, interchangeability of subjects and of meanings, haste and repetitions, thoughts "jumping" from subject to subject, skipping essential elements of language and resulting destruction of meaning, can thus be presented as being temporal in their origin. In turn, the suddenness of experiences and breaks in continuity affect personal development. The patients' inner life story cannot unfold. A manic person's existence is "ahistorical" (Binswanger 1964). ${ }^{2}$

\section{Phenomenology of the manic self: Lived experience}

Following classic phenomenological studies by Minkowski and Binswanger, we shall now elaborate on the characteristics of the manic self with respect to time. As noticed earlier, beyond the affective dimension of acceleration, mania is a disorder of temporality in the sense that people with mania live exclusively in the present and hardly at all into the future. Their "temporality of becoming" (von Gebsattel 1954) seems to be fully destroyed. The manic self-neither grows nor declines. Rather, it appears "frozen" in present time instants, except that (unlike in depressive states, which may also seem "frozen") it makes a lot of ostensible temporal moves. These moves are all in time, but they are not temporal.

An insightful and articulate person experienced in mania, who has had six episodes of manic psychosis during the last fifteen years, says that (person \#1): "time is a critical aspect of that experience... one's sense of time being profoundly altered during those experiences". The person asserts that (person \#1): "When you are very manic you are actually coming into the present moment". How can we further describe this momentary present? The person goes on to compare the experience with mindfulness meditation. In the latter, however, the

\footnotetext{
${ }^{2}$ In a short 1960 book on melancholia and mania, representing his second Husserlian phase (Spiegelberg 1972), Binswanger approached mania differently - as a disorder of transcendental constitution of the world. Taking advantage of the Husserlian notion of "appresentation" (from his Cartesian Meditations), Binswanger described the manic self as suffering from the psychotic loss of the common world. Manic people, Binswanger argued, lack appresentation as a precognitive (implicit) capability that normally enables seeing the other as an alter ego. As a result, they are unable to form relationships with others. Other egos, not fully constituted, remain strange or even reified, and become mere means towards ends (Binswanger 1994). Binswanger changed the meaning of the term appresentation, which for Husserl denoted the presence of absent aspects of an object in the act of perception. For Binswanger, it now referred to the domain of intersubjectivity.
} 
mind is fully present in a peaceful way. In mania, in contrast, the present is painful because the mind goes extremely fast while simultaneously experiencing high amounts of energy. Our subject also speaks of an extreme fear that has no temporal boundaries and is not objectrelated. The past and future are gone. (Person \#1): "It's like having this awareness, an almost physical sense of just having something that is not changing, that is just present. I mean it sounds maybe overly blunt to describe it as some sense of eternity, but that feels accurate. So there is no past, there is no future, you are just in the nowness, and that's so terrifying because I think it's so rare as most of us aren't in that most of the time". Since the conceptions of the present as, on the one hand, a dimension of time, and, on the other hand, as eternity, seem conceptually incompatible, our subject is asked to clarify what these notions mean. The present is then pictured as closer to being atemporal and, hence, unlike the ordinary, transient present. It is a felt sense of timelessness that is accelerated. (Person \#1): "It feels as though your body is lightening, it is a good image of that level of intensity. You are the lightning (...) Your brain is going so incredibly fast that you are coming with a million and one theories a moment, and you are trying to look for every sense of threat in your environment. It's like being hypersensitive (...). I guess, a lot of the reason your mind is going so fast is because you are so trying to make sense of what the hell is going on, if you are feeling like lightning (...) A lot to cope with so your brain is going very, very fast, and actually a lot of that is trying to re-process, re-examine stuff from the past, re-frame it".

The experience of being overwhelmed by sensations, regardless of their objective quantity, is common in mania. It may partly account for the sense of atemporality. The opposite of manic agitation, boredom, can be temporarily defined as a consequence of a static informational environment, which results in allocating more attention to timing and the pararell experience of time slowing in prospective judgment (Zakay 2014). In mania, reversely, the sense of acceleration could stem from a total allocation of reflective capacities upon the abundance of sensations. As a result, there would be no or few cognitive resources left for timing. When crossing a threshold, a total lack of attention to timing could explain the feeling of timelessness.

Another subject, one reportedly diagnosed with a hypomanic episode, describes the moments before the outburst of psychosis as (person \#2): "Explosion of happenings in the little amount of time" and a sense of acceleration "skipping into next few moments". It is an experience of approaching something indefinite. (Person \#2): "There was a black hole at the end of time pulling me in" (the person quoted apparently used this metaphor without knowing about the gravitational time dilation in the black hole). "At the end, everything paused (...) Like you took a three-dimensional snapshot of reality". Even the clock "stopped at that time." The experience "seemed eternal (...) Seemed not to be much distinction between subject and object". Asked to clarify, the individual stated that the experience was one of "timelessness".

\section{Phenomenology of the manic self: The future is now}

Minkowski and Binswanger observed sudden breaks of continuity of lived time in mania as well as the punctual character of the lived present. From the first-person perspective, we have seen further on, the experience was reported as quasi-eternal. How to reconcile these reports of timelessness with being in the discontinuous present? Bringing in the so-far missing notion of the future will help us clarify this issue. 
Let us first look at Binswanger's metaphors in the same vein as he looked at his patients' everyday language - as a means to disclose their ways of being better than conventional symptomatology (Lanzoni 2005). Binswanger's favorite metaphors describing the manic thinking are spatial - "jumping," "flying," "mounting," but they can all be read temporarily as well. The eradication of a spatial distance would then imply the eradication of the temporal one. A jump, an abrupt detachment from a space here towards a space there, is also an abrupt break in continuity. And if "there" is later than "here," it is a leap towards the future as well.

In contrast to melancholia, and significantly different than schizophrenia, mania may involve a sense of freedom over the future (Sass and Pienkos 2013). Manic persons not only are more impulsive but also have unrealistic goals and grandiose visions of what is possible (Gruber et al. 2012). The increase of conation, inevitably, accelerates them ahead of others (Fuchs 2013), but there is also a qualitative change involved. The stage of manic psychosis in regard to time does not merely consist of subjectively experienced acceleration of thoughts and concomitant affectivity, but in realizing a distant (and at best potential, if possible at all) future in the present. Indeed, characteristic manic delusions often entail experiencing an impossible, imagined future self in the very present moment. "I want to be a chef, a model, an architect, a surgeon, and an astronaut" (Behrman 2003).

A manic person rebels against the facticity of existence. The here and now is his enemy. Manic excitement covers the impossibility of accepting the limits of the present, and it bears a certain resemblance to the ecstatic Rausch of an addict (Moskalewicz 2016). A manic person yearns for change and breaks away from the present. It is the very finitude of human existence that evokes the rebellion. While it is normal to move away from any given facticity, there are limits of what can be changed that are generally accepted. The manic movement, in contrast, becomes unusually intense. A study found that the mere feeling of power leads to an experience of having more time at one's disposal (Moon and Chen 2014). We can speculate that the deceptive feeling of being almighty - the manic superman syndrome (Salvatore et al. 2012) - leads to a sense of having one's future self already at hand and, therefore, abandoning normal temporal structure of experience altogether (or rather, that these - affectivity and temporality are the two sides of the same coin). A subject experiences unconstrained, unstructured, but overly enticing possibilities - the phenomenon that has been termed the "decontextualization of possibilities" or an "endless possibility" (Bowden 2013: p. 115). The latter concept indicates that it is not simply a matter of the abundance of possibilities. Endless possibility implies that no possibility, no anticipation, can be fulfilled on principle, and no future beyond the now can actually take place. Bowden calls it a "radical reinterpretation" of the manic self (Bowden 2013). It is radical because it lacks a distinct horizon of the future. Despite the rebellion against facticity, only the immediate now is important. The manic self is immersed in the now and lacks a reflective distance towards time. There is little or no consideration for the consequences of actions. As far as such a radical interpretation implies immobilizing the manic self in its becoming, it is also characteristic of psychotic temporal experience in general (Moskalewicz 2018). Mania thus impinges on the ordinary temporal structure of lived experience, in which the dimensions of the past space of experience and the future horizon of expectation meet in the extended present.

One cannot experience one's future otherwise than as a horizon of the present. In mania, it is as if the future has already happened. If, in his delusional world, one has 
already existentially moved his self radically forward, one then has no future besides the present. The future is only the future of the self, and not of the world. In this sense, the self and the world become disconnected, and only the former progresses, which disintegrates the normally continuous temporal structure of experience. The future that is now is neither a present (since the latter requires a distinct future horizon to be a present), nor a future (which is just a horizon of the present). Therefore, the present lived experience of a manic person is not temporal. As behind the manic excitement lurks sadness (Binswanger 1964), the future that is now paradoxically reveals its atemporality. Manic persons refute the inescapable temporality of human existence and it is precisely why mania is an illness - the temporal foundations of being cannot be disregarded without adverse consequences. Timelessness thus goes along with living the discontinuous present. The rebellion against the here and now is a permanent struggle that must be renewed again and again.

Our interviewee also interpreted grandiosity as a symptom of temporal disturbance - of (person \#1): "Getting stuck in the forever." The sense of self shifts radically towards the future, and the previous self suddenly seems totally inaccurate. The person thinks this is a result of acceleration. (Person \#1): "The level of energy coming through your body, the intensity of the physical experience I guess is equally driving kind of energy in your brain, is such that actually you relate much, much more to not being this entity, just to being human. I think in that state I would just describe myself as human, you know, I wouldn't say I am X, and define myself in that way, although I would probably be able to relate to that (...). So I can understand how people then get drawn to saying 'I am Jesus' or 'I am this,' picking significant figures, cause that's exactly what is going on through people, that usual sense of self is completely insufficient. It is making sense of what you are going through". The new sense of self expands beyond previous (and normal) temporal boundaries. As we have noticed, present and future lose their usual meaning, as there is no longer any future, and hence no present - the fact that can explain the feeling of timelessness. One's wishes, dreams, hopes, and aspirations cannot be fulfilled.

One important question remains though - whether the above remarks address merely the level of lived conscious experience of time, the so-called explicit temporality (Fuchs 2013) or do they stem from a more fundamental implicit or internal time, to use Husserl's term (Husserl 1991). In Melancholie und Manie Binswanger interpreted mania as a failure of the temporal constitution of the world, that is as operating at a more implicit level (Binswanger 1994). However, Binswanger misinterpreted Husserl notions of retention and protention, and considered them as pertaining to the conscious level of experience of past and future. The structure of manic temporality was described as a loss of binding between these different dimensions of explicit temporal consciousness resulting in fragmented, isolated pieces of the present. If taking place at the level of retentional-protentional coherence, such a loss of binding is today associated with schizophrenia rather than with mania (Giersch and Mishara 2017). Binswanger, however, might have been right in being wrong, if we allow for the possibility of the disruption of temporal experience in mania to stem from a more fundamental, constitutive level of consciousness. Bowden's phenomenological study presents a safe position in this respect, arguing that in mania the implicit temporal synthesis is weakened but not broken (Bowden 2013). Contrary to Thomas Fuchs' theory, this view entails that mania affects not only conation but also passive temporal synthesis (as does schizophrenia). In particular, the weakening of retention, that is pre-reflective awareness of the immediate past, can explain the excess of possibilities. In that case, the lived past does 
not (pre-reflectively) constrain the lived future. It is easier for a manic person to abandon previous responsibilities and engage with the world in a way unrestrained by previous experiences. These thoughts on the implicit "cut-off" from the past are in line with our thesis on the presentation of the future possibilities in the now. Even if the experience of atemporality can be explained cognitively at the level of reflective consciousness by a total lack of attention to timing (as hypothesized earlier), the more existential aspects of lived time - the discontinuity of the self and the paradoxical leap towards the future - presuppose some sort of disruption of a more basic structure of temporality.

\section{Biological clocks, lithium, and mania}

Can we, in any precise manner, begin to reconcile the varied phenomena described above with contemporary neuroscience and the emerging neurobiology of mania? In this section, answering "apparently yes," we will focus upon the master clock in the human brain, the suprachiasmatic nucleus $(\mathrm{SCN})$, and the remarkable fact that this clock affords receptor sites for lithium - a foundational pharmacological treatment for mania. By binding to the SCN, and potently inhibiting the biological cascade created by the SCN (Abe et al. 2000), lithium disrupts manic temporality dysregulation and restores a more "normalized" temporal experience. Core insights into the disorder result, as well as core treatment implications.

The SCN - a tiny region of the brain located in the hypothalamus directly above the optic chiasm, and comprising approximately 20,000 neurons - is our organism's "master clock." As such, the SCN controls our circadian rhythms. Such a clock is needed because organisms in our world must adapt to two major periodic variations, seasonal changes and the 24-h light-dark cycle. Mammalian organisms use more than one clock to keep track of time, and circadian rhythms associated with causal mechanisms have been found in many bodily tissues. Importantly, however, all of these peripheral clocks are driven by the SCN's master pacemaker (Welsh et al. 2010).

Over past decades, a growing functional understanding of operative mechanisms in the SCN has been underway (Silver and Schwartz 2005). Neurons in the SCN directly receive information about light/dark from photoreceptors in the retina. Fundamentally, in its capacity to keep track of time (for example, of the extended passage of a day's light) the SCN functions in the manner of an ancient "water clock" (Phelps 2014; McNown 1976). Such clocks, in existence throughout the ancient world, relied upon a flow of water to measure time. Two types of water clocks existed: inflow clocks and outflow clocks. In an outflow water clock, a container is filled with water, and the water would drain slowly and evenly out of the container. Markings on the container would show the passage of time. As the water drained out, observing markings on the container would disclose how much time had passed. Inflow clocks worked in the same manner, except that water flowing in would gradually fill up the container. Again, markings on the container could tell an informer how much time had passed. The latter - an "inflow water clock" - presents a model to facilitate understanding of the time-keeping capacity of the SCN. It is because in the SCN, time passage is marked by the amount of time it takes for DNA instructions from transcription factors to create a protein molecule. The process starts when promoter transmission factors - BMAL1 and CLOCK - interact with DNA within cells in the SCN and activate messenger RNA which conveys genetic information from the DNA to ribosomes, leading 
to protein products Per and Cry. In turn, when produced, Per and Cry act as repressor proteins which bind promoter transmission factors BMAL1 and CLOCK and turn the whole process off. When the process is turned off, using our analogy, the water bowl of the water clock is empty, and an interval of time - a day - has passed (Buhr and Takahashi 2013). Next, the process must be turned on once more so that the process can run over again. Consequently, the repressor protein products Per and Cry are gradually degraded by a phosphate molecule being attached to them. After Per and Cry are degraded, we are back to the starting point, and the process can begin once again (Buhr and Takahashi 2013).

Importantly, the above cycle cannot be rigidly determined. Timing must be synchronized with different day lengths across changing seasons - with longer day lengths in summer and shorter day lengths in winter. The determining factor is light. When sunlight disappears, another repressor protein, Rev-erba is produced. Rev-erba binds to DNA and blocks the entire process from starting. The following day, sunlight appears in the morning, inactivates/degrades Rev-erba, and starts the clock again. Internally, within the organism, a "new day" can dawn (Crumbley and Burris 2011). How does lithium impinge upon this process? Through its interaction with an enzyme, glycogen synthase kinase-3- $\beta$ (GSK3- $\beta$ ). This enzyme, GSK3- $\beta$, blocks the inactivation/ degradation of Rev-erba. Importantly, lithium inhibits GSK3- $\beta$ (Brown and Tracy 2013). Furthermore, so do other mood stabilizers, such as valproic acid and lamotrigine (Coyle 2007). Lithium has been shown to slow the internal clock at night and despite diurnal variations bring more balanced judgments between day and night as measured by time estimation tasks of short intervals in bipolar patients (Elsass et al. 1979).

Additional discoveries in contemporary neuroscience correlate with these findings. Manic acceleration has been related to changes in circadian rhythms. A shorter circadian period has been observed in some patients during weeks-long isolation from external zeitgebers (Wehr et al. 1985), and manic patients tend to have faster than average periodicity (Salvatore et al. 2012). Furthermore, individuals with a previous history of mood disorder show an increased rate of manic/hypomanic episodes with transmeridian eastward travel. They appear to be more vulnerable if adherence to medication is compromised (Inder et al. 2016). Finally, mice carrying a mutation in the CLOCK gene display an overall behavioral profile that has been characterized as "strikingly similar to human mania, including hyperactivity, decreased sleep, lowered depression-like behavior, lower anxiety, and an increase in the reward value for cocaine, sucrose, and medial forebrain bundle stimulation." Interestingly, administration of lithium returns many of these behaviors to wild-type levels (Roybal et al. 2007).

Present-day neuroscience offers relevant insights assisting both the comprehension of the phenomenon of manic experience and pharmacological and nonpharmacological treatment/stabilizing approaches. These ideas afford potent options for persons with mania, their families, and those who care for them. And they offer some biological clues regarding the mysteries surrounding human temporality as a fundamental mode of our being-in-the-world.

\section{Temporal collapse and cognitive orientation in time in mania}

Interestingly, despite the biological and existential temporal collapse, patients in manic psychosis rarely experience cognitive disorientation in clock time. While their natural 
rhythms are deregulated and existential becoming disrupted, clock time comprehension remains mostly untouched. Typically, manic persons can correctly assess their age, indicate precisely the day of the week, and come on time for a meeting with a doctor. Even if their circadian rhythms and lived time are profoundly transfigured and disconnected from the public, intersubjective temporal world, their time orientation remains in place.

A person experienced in mania asked about what happens with the ordinary sense of time during a manic episode, in which the felt sense of time is deeply disrupted, says that (person \#1): "It is very hard to describe (...) It is like literally being at two places at once if that makes sense (...) It's like a part of you is just in a sense of eternity, I suppose, some expanded state of consciousness or awareness, and then the other part of you is aware that you are living in a temporal world and, you know, life goes on, there is a clock and there is time, but your relationship to that, on another level, is profoundly altered. It feels so... I guess your normal executive functions are trying to function within that normal clock time because you recognize that this is what normal people do and this is what you traditionally do in your life, but your felt sense is totally different to that cognitive sense, if that is understandable?"

When asked to elucidate further, the person continues to explain that time has a double meaning during a manic episode. The cognitive orientation is not affected but, crucially, it may seem affected due to being disregarded by the subject (who, as we speculated earlier, does not allocate his cognitive resources to timing in the conventional sense). The person recalls being asked when the First World War was. (Person \#1): "I did history A-level, and of course, I knew when the First World War was, but it seemed to me at that time, after everything I experienced, totally absurd. (...) That seemed utterly ludicrous. So my interpretation of that was 'when was the first conflict between good and evil. When was the first friction'? (...) I was like having two answers all of the time. I could give him [the doctor] a correct answer, but I think the answer I actually gave him about that particular WWI was 'BC,' by which I meant not before Christ, I just meant 'when was the first conflict between good and evil, light and dark'".

Even though people suffering from mania may remain in touch with clock time, they do not establish a meaningful relationship with it. Clock time categories, which are typically taken advantage of in existential becoming - in the sense that they enable one to orient oneself in the public time, localize one's memories and plans on a timeline, and rationalize the latter for the sake of achieving short and long-term life goals - lose their personal significance. Clock time categories are, therefore, detached from lived experience, and operate in a depersonalized form.

The subject later describes the two possible answers to the question of clock time as a big and a small answer. Asked about how long the experience of eternity had last in terms of clock time, the person gives a small answer in retrospection. However, if had been actually asked during an episode, the person says (person \#1): "I would probably give you a big answer and part of me at the same time would recognize that there is a small answer, and a small answer would be five or six days. I think I would know it and that is what maybe stops me from sliding off into frank psychosis. There is a part of me which can keep that executive function just enough on... but, yeah, there is another part which would give you a big answer of, you know, I have been here since eternity, since forever, since when was the world made, when was the big bang, and probably go off into that very expanded answer. But being able to keep hold of that equally, the five or six days, I mean, I think that's the art of actually surviving these experiences without them completely dominating your entire life, and throwing you into place when you're locked up forever". 


\section{Time as a treatment}

So far, we have left the question of treatment out of considerations. Are there, in addition to lithium and other mood stabilizers, non-pharmacological approaches to treating, minimizing and stabilizing manic events? Emerging evidence exists demonstrating a stabilizing effect when social rhythm stability is incorporated into one's daily routines and, in contrast, destabilization when such stability is disregarded. It is most likely the rhythm itself, regardless of its origin, that has that stabilizing effect. In undergraduates with bipolar spectrum disorders, social rhythm inconsistency is associated with a shorter time to an affective episode (Shen et al. 2008). Additionally, social rhythm inconsistency is linked to the development of bipolar disorder in high rewardsensitivity adolescents (Alloy et al. 2015). Furthermore, in a sample of patients with bipolar disorder, events linked with disruptions in social rhythms (e.g., overseas travel, being fired from a full-time job, marital separation) better predict manic episodes than severe life events in general (Malkoff-Schwartz et al. 1998).

Social rhythm stability can be facilitated, for example, through regard for and incorporation of zeitgebers into one's daily routine. A zeitgeber is an external or environmental cue that entrains/synchronizes an organism's biological rhythms to the earth's 24-h light/ dark or 12-months cycle. Examples include attunement to the rising and setting of the sun, or, for example, walking the dog first thing in the morning and just before sunset. Consequent to the above, social rhythm therapies (SRTs) have been devised and formularized to support recovery and stability in persons with bipolar disorder (Frank et al. 2005). SRTs support the implementation of regular, daily patterns of activity to facilitate the recovery of circadian biological processes and to improve mood. They incorporate engagement in a moderate amount of activities at a habitual time each day in order to promote stability (Haynes et al. 2016). Emerging data is encouraging.

\section{Conclusions}

We have argued that manic temporality is the link through which manic neurobiology and manic phenomenology intertwine. Their intertwining, however, does not mean that the gap between the two domains can be fully bridged. Speaking of manic neurobiology it is important to emphasize that besides the master SCN, there are other structures coding temporal experience, such as the hippocampus and the striatum (Presti 2016). Time reproduction tasks prove specifically that a memory component is relevant. Even within the quantitative assessments paradigm, there is more to the story of the temporal experience in mania than a pulsing mechanism of an internal clock (Mahlberg et al. 2008). Therefore, the origin of temporal experience in mania almost certainly cannot be reduced to distorted circadian rhythms. It also remains unclear how to translate the circadian pattern that synchronizes organisms with the cosmic environment into lived experience that involves past, present, and future. No simple causal mechanism could explain the lived experience of time, not to mention the fact that the brain itself is plastic and dialogically interacts with lived experience. Even if neurobiology is the ground, it is a non-determining one. The major methodological limitation, moreover, has to do with the quantitative approach towards temporal experience. Time perception tasks by necessity concern time elapsed or elapsing (past-present or present-past 
relation), but not the present-future relation (Straus 1978). But even if the neuroscientific and phenomenological projects are not entirely reconcilable, bridges between the two domains can and should be built.

The more comprehensive character of phenomenological investigation has the capacity to bind together the results of natural-scientific studies with the actual first-person experiences. Our analysis presented the existential temporal characteristics of the manic self as fundamentally altered. Such a self, not living into the future, but for which the content of the future self is already at hand, inhabits a lifeworld of its own. In mania, the bond between the felt sense of time and the cognitive comprehension of clock time, which loses its usual orienting function, breaks. Mania is a rebellion against the limiting facticity of existence. A leap towards the future is ultimately a leap beyond temporality, one that results in quasi-eternal or timeless (regarding the ordinary sense of time at least) experience. The manic fusion of present and future is not temporal. Being locked in the now that is devoid of past and future equals living an atemporal and therefore false existence.

Acknowledgements The paper was written during Marcin Moskalewicz's Marie Curie Fellowship at the Faculty of Philosophy, University of Oxford. The project has received funding from the European Union's Horizon 2020 research and innovation programme under the Marie Sklodowska-Curie grant agreement No 659205 .

Compliance with ethical standards An informed consent concerning the publication of results was obtained from all persons interviewed in this paper. The interviews were conducted by Marcin Moskalewicz.

Open Access This article is distributed under the terms of the Creative Commons Attribution 4.0 International License (http://creativecommons.org/licenses/by/4.0/), which permits unrestricted use, distribution, and reproduction in any medium, provided you give appropriate credit to the original author(s) and the source, provide a link to the Creative Commons license, and indicate if changes were made.

\section{References}

Abe, M., Herzog, E. D., \& Block, G. D. (2000). Lithium lengthens the circadian period of individual suprachiasmatic nucleus neurons. Neuroreport, 11, 3261-3264.

Alloy, L. B., Boland, E. M., Ng, T. H., Whitehouse, W. G., \& Abramson, L. Y. (2015). Low social rhythm regularity predicts first onset of bipolar spectrum disorders among at-risk individuals with reward hypersensitivity. Journal of Abnormal Psychology, 124, 944-952.

Angst, J. (2007). The bipolar spectrum. The British journal of psychiatry : The journal of mental science, 190(1922), 189-191.

Behrman, A. (2003). Electroboy: A memoir of mania. New York: Random House.

Binswanger, L. (1964). On the manic mode of being-in-the-world. In E. W. Straus (Ed.), Phenomenology: Pure and Applied. Pittsburgh: Duquesne (pp. 127-141). University Press.

Binswanger, L. (1992). Über Ideenflucht. In M. Herzog (Ed.), Ausgewählte Werke Band 1 (pp. 1-231). Heidelberg: Roland Asanger Verlag.

Binswanger, L. (1994). Melancholie und Manie. In A. Holzhey-Kunz (Ed.), Ausgewählte Werke Band 4 (pp. 351-428). Heidelberg: Roland Asanger Verlag.

Bowden, H. M. (2013). A phenomenological study of mania and depression. Durham theses: Durham University. Available at: http://etheses.dur.ac.uk/9456/ .

Brown, K. M., \& Tracy, D. K. (2013). Lithium: The Pharmacodynamic actions of the amazing ion. Ther Adv Psychopharmacol., 3(3), 163-176.

Buhr, E. D., \& Takahashi, J. S. (2013). Molecular components of the mammalian circadian clock. Handbook of Experimental Pharmacology, 217, 3-27.

Colillas, I. I. (2016). Los Trastornos Bipolares: Una Revision Critica. Psicopatologia, Historia Y Epistemologia. Letra: Viva. 
Coyle, J. T. (2007). What can a clock mutation in mice tell us about bipolar disorder? PNAS, 104(15), 60976098.

Crumbley, C., \& Burris, T. P. (2011). Direct regulation of CLOCK expression by REV-ERB. PLoS One, 6(3), e17290.

Elsass, P., et al. (1979). Lithium effects on time estimation and mood in manic-melancholic patients. A study of diurnal variations. Acta Psychiatrica Scandinavica, 60(3), 263-271.

Frank, E., Kupfer, D. J., Thase, M. E., Mallinger, A. G., Swartz, H. A., Fagiolini, A. M., Grochocinski, V., Houck, P., Scott, J., Thompson, W., \& Monk, T. (2005). Two-year outcomes for interpersonal and social rhythm therapy in individuals with bipolar I disorder. Archives of General Psychiatry, 62, 996-1004.

Fuchs, T. (2013). Temporality and psychopathology. Phenomenology and the Cognitive Sciences, 12(1), 75104.

von Gebsattel, V. E. F. (1954). Prolegomena einer Medizinischen Anthropologie. Berlin, Göttingen, Heidelberg: Springer Verlag.

Giersch, A., \& Mishara, A. (2017). Disrupted continuity of subjective time in the milliseconds range in the self-disturbances of schizophrenia. Journal of Consciousness Studies, 24(3-4), 62-87.

Gruber, J., et al. (2012). Feeling stuck in the present? Mania proneness and history associated with presentoriented time perspective. Emotion, 12(1), 13-17.

Haynes, P. L., Gengler, D., \& Kelly, M. (2016). Social rhythm therapies for mood disorder disorders: An update. Current Psychiatry Reports, 18, 75.

Husserl, E. (1991). On the Phenomenology of the Consciousness of Internal Time (1893-1917), Dordrecht. Boston, London: Kluwer Academic Publishers.

Inder, M. L., Crowe, M. T., \& Porter, R. (2016). Effect of transmeridian travel and jetlag on mood disorders: Evidence and implications. Australian \& New Zealand Journal of Psychiatry, 50(3), 220-227.

Katzow, J. J., Hsu, D. J., \& Ghaemi, S. N. (2003). The bipolar spectrum: A clinical perspective. Bipolar Disorders, 5(6), 436-442.

Lanzoni, S. (2005). The enigma of subjectivity: Ludwig Binswanger's existential anthropology of mania. History of the Human Sciences, 18(2), 23-41.

Lehmann, H. E. (1967). Time and psychopathology. Annals of the New York Academy of Sciences, 138(2), 798-821.

Mahlberg, R., Kienast, T., Bschor, T., \& Adli, M. (2008). Evaluation of time memory in acutely depressed patients, manic patients, and healthy controls using a time reproduction task. European Psychiatry, 23(6), $430-433$.

Malkoff-Schwartz, S., Frank, E., Anderson, B., Sherrill, J. T., Siegel, L., Patterson, D., \& Kupfer, D. J. (1998). Stressful life events and social rhythm disruption in the onset of manic and depressive bipolar episodes: A preliminary investigation. Archives of General Psychiatry, 55, 702-707.

McNown, J. S. (1976). When time flowed: The story of the clepsydra. La Houille Blanche, (5), 347-353.

Mezey, A. G., \& Knight, E. J. (1965). Time sense in hypomanic illness. Archives of General Psychiatry, 12, $184-186$.

Minkowski, E. (1970). Lived Time. Phenomenological and Psychopathological Studies, Evanston: Northwestern. University Press.

Moon, A., \& Chen, S. (2014). The power to control time: Power influences how much time (you think) you have. Journal of Experimental Social Psychology, 54, 97-101.

Moskalewicz, M. (2016). Lived time disturbances of drug addiction therapy newcomers. A qualitative, field phenomenology case study at Monar-Markot Center in Poland. International Journal of Mental Health and Addiction, 14(6), 1023-1038.

Moskalewicz, M. (2018). Toward a unified view of time: Erwin W. Straus' phenomenological psychopathology of temporal experience. Phenomenology and the Cognitive Sciences, 17(1), 65-80.

Nielzén, S., \& Cesarec, Z. (1982). Aspects of tempo and perception of music in mania. Acta Psychiatrica Scandinavica, 65(2), 81-85.

Phelps, J.R. (2014). How does the biological clock work? (and lithium). Psycheducation.org http://psycheducation.org/treatment/bipolar-disorder-light-and-darkness/the-biological-clock-light-andlithium/

Presti, D., 2016. Foundational concepts in neuroscience. A brain-mind odyssey, New York, London: W. W. Norton \& Company.

Pronin, E., \& Jacobs, E. (2008). Thought speed, mood, and the experience of mental motion. Perspectives on psychological science : a journal of the Association for Psychological Science, 3(6), 461-485.

Pronin, E., \& Wegner, D. M. (2006). Manic thinking: Independent effects of thought speed and thought content on mood. Psychological Science, 17(9), 807-813. 
Pronin, E., Jacobs, E., \& Wegner, D. M. (2008). Psychological effects of thought acceleration. Emotion (Washington, D.C.), 8(5), 597-612.

Roybal, K., Theobold, D., Graham, A., DiNieri, J. A., Russo, S. J., Krishnan, V., Chakravarty, S., Peevey, J., Oehrlein, N., Birnbaum, S., Vitalerna, M. H., Orsulak, P., Takahashi, J. S., Nesler, E. J., Carlezon, W. A., \& McClung, C. A. (2007). Mania-like behavior induced by disruption of CLOCK. Proceedings of the National Academy of Sciences, 104(15), 6406-6411.

Salvatore, P., et al. (2012). Biological rhytms and mood disorders. Dialogues in Clinical Neuroscience, 14(4), 369-379.

Sass, L. A., \& Pienkos, E. (2013). Space, time, and atmosphere: A comparative phenomenology of melancholia, mania, and schizophrenia, part II. Journal of Consciousness Studies, 7-8, 131-152.

Shen, G. H. C., Alloy, L. B., Abramson, L. Y., \& Sylvia, L. G. (2008). Social rhythm regularity and the onset of affective episodes in bipolar spectrum individuals. Bipolar Disorders, 10, 520-529.

Silver, R., \& Schwartz, W. J. (2005). The suprachiasmatic nucleus is a functionally heterogeneous timekeeping organ. Methods in Enzymology, 393, 451-465.

Spiegelberg, H., 1972. Phenomenology in Psychology and Psychiatry. A Historical Introduction, Evanston: Northwestern University Press.

Stein, J. (1977). Tempo errors and mania. The American Journal of Psychiatry, 134(4), 454-456.

Stein, J. (1988). Manic tempo misperceptions. Biological Psychiatry, 24(4), 492.

Straus, E. (1978). Vom Sinn der Sinne. In Ein Beitrag zur Grundlegung der Psychologie. Berlin, Heidelberg, New York: Springer Verlag.

Tysk, L. (1984). Time perception and affective disorders. Perceptual and Motor Skills, 58(2), 455-464.

Tysk, L. (1985). Longitudinal changes in time estimation in affective disorders: A preliminary study. Perceptual and Motor Skills, 60(1), 179-188.

Wehr, T. A., Sack, D. A., Duncan, W. C., Mendelson, W. B., Rosenthal, N. E., Gillin, J. C., \& Goodwin, F. K. (1985). Sleep and circadian rhythms in affective patients isolated from external time cues. Psychiatry Research, 15(4), 327-339.

Welsh, D. K., Takahashi, J. S., \& Kay, S. A. (2010). Suprachiasmatic nucleus: Cell autonomy and network properties. Annual Review of Physiology, 72, 551-577.

Zakay, D. (2014). Psychological time as information: The case of boredom. Frontiers in Psychology, $5,917$. 